\title{
ARTÍCULO
}

\section{La readmisión de extranjeros en situación irregular entre Estados miembros: consecuencias empírico-jurídicas de la gestión policial de las fronteras internas}

\section{The Readmission of Irregular Foreigner Within European Member States: Socio-Legal Consequences of a Police Management of The Internal Borders}

\author{
Iker Barbero \\ Departamento de Derecho Administrativo, Constitucional y Filosofía del Derecho. \\ Universidad del País Vasco-Euskal Herriko Unibertsitatea
}

Fecha de recepción 06/06/2017 | De aceptación: 01/12/2017 | De publicación: 27/12/2017

\section{RESUMEN.}

La comisaría de Policía Nacional de Irun, ciudad situada en la frontera con el Estado francés, en comparación con otras comisarías de la Comunidad Autónoma del País Vasco, tiene los datos más altos de arrestos de extranjeros en situación irregular. Aunque es común encontrar controles policiales cerca del entorno fronterizo, esto choca con la idea de la Unión Europea sin fronteras. El lugar donde estaba una de los puestos fronterizos ha sido ocupado por un peaje de automóviles construido con una estructura muy particular: con cámaras de vigilancia, con garitas para policías, etc. El $70 \%$ de las personas detenidas en el Centro de Detención Administrativa de Hendaia en 2015 fueron capturadas en la frontera. Además, los datos de readmisión fronteriza entre los dos Estados, en virtud de un acuerdo firmado en 2002, son significativos: 6.000 personas han sido expulsadas de media anual a lo largo de la frontera, en los últimos tiempos. Este análisis de la frontera hispano-francesa pretende ser un estudio exploratorio de una temática desatendida: las fronteras internas de la UE. La regulación en estas áreas es diversa. Muchas excepciones y especificidades se aplican, paralelamente o alternativamente a las normas ordinarias de inmigración de los Estados miembros. Teniendo en cuenta todo esto, tenemos que repensar el imaginario de una Europa sin fronteras que se afirma en el Acuerdo de Schengen. Las fronteras interiores de la UE nunca han desaparecido, sino que han mutado en un modelo de gestión policial de las fronteras internas

\section{PALABRAS CLAVE.}

Fronteras internas, España-Francia, acuerdos readmisión, Derechos fundamentales

\section{ABSTRACT,}

The police station in Irun, a town close to the border between the Spain and France, compared to other police stations in the Basque Country has the highest data of arrests of foreigners in irregular situation. It is common to find identity police controls near the border surroundings (roads, trains stations, the border surroundings, etc). In addition, the data of border readmission between these two states, under an agreement signed in 2002, is something to look at with special attention: 300.000 people have been deported along this internal border. Finally, $70 \%$ of the people detained in the French Detention Centre of Hendaia in 2015 were caught especially at the border crossing. For these reasons, this case study of the SpanishFrench border will put some light in a disregarded topic and object: the internal borders. Many exceptions apply, parallel or alternatively to the ordinary immigration rules, as a matter of exception of the Law. Considering all this, we need to rethink the mith of a borderless Europe stated by the Schengen agreement. The EU internal borders never disappeared but mutated into a police managed model of internal borders.

\section{KEY WORDS.}

Internal borders, Spain-France, readmission agreements, Fundamental Rights 
Tabla 1: Detenciones por Ley de Extranjería en el

País Vasco (2008-2010)

\section{Introducción ${ }^{1}$}

Si miramos los datos de detención de extranjeros en el País Vasco ${ }^{2}$, observamos que en la provincia de Gipuzkoa se producen muchas más detenciones por Ley de extranjería que las otras dos provincias (Bizkaia y Araba). Sin embargo, Gipuzkoa no presenta características poblacionales de extranjería muy diferentes que justifique esa desproporción (Gipuzkoa 8,8\% población extranjera, Bizkaia $8 \%$ y Araba $10,5 \%)$.

\begin{tabular}{|c|c|c|c|c|c|c|}
\hline Año & Bizkaia & Araba & $\begin{array}{c}\text { Gip } \\
\text { SS }\end{array}$ & $\begin{array}{c}\text { Gip } \\
\text { Irun }\end{array}$ & $\begin{array}{c}\text { Total } \\
\text { CAV }\end{array}$ & $\begin{array}{c}\text { Total } \\
\text { Estado }\end{array}$ \\
\hline 2008 & 291 & 247 & 381 & 710 & 1.629 & 92.869 \\
\hline 2009 & 373 & 261 & 351 & 745 & 1.730 & 03.904 \\
\hline 2010 & 337 & 303 & 393 & 587 & 1.620 & 86.060 \\
\hline 2011 & 289 & 369 & 463 & 818 & 1.939 & 90.425 \\
\hline 2012 & 446 & 341 & 533 & 976 & 2.296 & 59.570 \\
\hline 2013 & 450 & 260 & 530 & 897 & 2.137 & 49.406 \\
\hline 2014 & 443 & 342 & 451 & 781 & 2.017 & 42.245 \\
\hline 2015 & 527 & 313 & 379 & 694 & 1.913 & 36.327 \\
\hline 2016 & 652 & 321 & & 1.34 & 2.307 & 35.882 \\
\hline
\end{tabular}

Fuente: Jefatura Superior de Policía del País Vasco y Defensor del Pueblo (MNPT)

Ahora bien, tras solicitar a la Jefatura Superior de Policía del País Vasco el desglose por comisarías en Gipuzkoa, observamos que si bien la comisaría de la capital provincial, Donostia-San Sebastian, guarda una relación con el resto de comisarías de capitales de provincia (unas 400 de media anual);

${ }^{1}$ Este artículo es fruto del trabajo llevado a cabo en el seno del Proyecto de investigación de la UPV-EHU, titulado IUSFUNDIE: Derechos fundamentales y formas actuales de detención, internamiento y expulsión de personas en situación administrativa irregular (US15/20) www.iusfundie.eu. Las principales ideas de este texto las desarrollé durante una estancia de investigación (octubre y noviembre de 2016), en el Institut d'études ibériques et ibérico-américaines - Droit et politique comparés y el Institut Universitaire Varenne de la Université de Pau et des Pays de l'Adour (UPPA), a quienes estoy muy agradecido por su amable acogida y puesta disposición de sus fondos bibliográficos.

2 Además, estos datos sitúan al País Vasco, aún lejos de las cifras de Madrid (6.333) pero cerca de Cataluña (2.735 con un 13\% de población extranjera), en unos términos de detención especialmente altos ( $\mathrm{Si}$ en 2008 eran 1629, en 2016 han sido 2307, mientras que en el Estado español de 92869 han caído hasta 35.882 personas detenidas)

la comisaría local de Irun, por el contrario, revela la magnitud de las cifras: en torno a 700-800-900 personas son detenidas anualmente. Sin embargo, esta localidad tampoco es espacialmente diversa en lo que a inmigración/extranjería se refiere. Irun cuenta con 7.357 personas de origen extranjero $(11,9 \%$ de la población total), la comarca del Bajo Bidasoa (11,1\%). El único carácter que la diferencia es la condición de "región fronteriza" con otro Estado Miembro: Francia. Al otro, en 
Cuadernos Electrónicos de Filosofía del Derecho

Hendaia, aunque un $36,4 \%$ se computa como extranjero, esta cifra responde en gran medida a personas prevenientes del otro lado de la frontera que han establecido su residencia debido, por una parte, al precio de la vivienda (la población extranjera en Departamento de Pirineos atlánticos representa un 4,8\%), y por otra a la creación de un estilo de vida transfronterizo incentivado por la incorporación de España al Espacio Schengen en 1993 (ratificado por España el 25 de junio de 1991) y la consideración de ciudadanos europeos con libertad de movimiento (Bray 2007). Por tanto debemos preguntarnos ¿Hasta qué punto el nivel de detenciones por situación irregular se debe a controles en la zona fronteriza?¿No se habían eliminado las fronteras e instaurado un régimen de libertad de circulación?

La redefinición de las fronteras europeas, exteriores e interiores, está en directa relación con la consideración de la inmigración irregular y la lucha contraterrorista como principales problemas sociales y políticos (Bigo et al 2015, Triandafyllidou 2016). La cada vez mayor securitización del territorio europeo (Huysmans 2006, Guild 2009) está poniendo en evidencia el supuesto desmantelamiento de las fronteras internas del Acuerdo de Schengen. Esta situación se ha visto agravada tras la vinculación que se ha construido entre los migrantes (y refugiados) provenientes de los países musulmanes y los atentados ocurridos en Francia o Alemania (Klepp 2010, De Lucas, 2015). Es lo que Didier Bigo ha denominado "Eurosurveillance" (2009). En la línea que plantea Bigo de tensión entre sistemas jurídicos estatales y el comunitario y la retórica de la securitización, la balanza cae del lado de la seguridad en detrimento de las garantías procesales y los derechos fundamentales. La libertad de circulación, como principio fundamental de la Unión Europea ha quedado en suspensión. El 25 de noviembre de 2015, el presidente de la Comisión Europea, Jean-Claude Juncker decía que "Schengen está parcialmente comatoso". Como veremos más adelante, es una crisis en la concepción de Libertad, Seguridad y Justicia derivada de la acción unilateral de los Estados miembros que optaron por reintroducir controles fronterizos con sus vecinos comunitarios. Sin embargo, en este estudio analizaremos el modelo de controles policiales no fronterizos aplicado en el contexto hispanofrancés como el modelo de gestión policial de las fronteras internas hacia el que tiende la Unión Europea. En cierto modo, estaríamos muy próximos a la concepción de "frontera interna" de Balibar, para quien "bajo ningún concepto ciertas fronteras se hayan ya situadas en las fronteras en el sentido geográfico-político-administrativo del término, sino que residen en otro sitio, dondequiera que ejerzan controles selectivos" (2005:84), a decenas de kilómetros del confín 
Cuadernos Electrónicos de Filosofía del Derecho

geográfico. Siguiendo a este autor francés, consideramos que lejos de eliminar las fronteras, se está desarrollando un sistema que busca ser más eficaz en el control selectivo, deteniendo mediante patrones de perfiles étnicos, y mediante la suspensión de derechos fundamentales. Por lo tanto, es necesario el estudio de la redefinición de facto de "frontera interna" como paradigma del control policial de la movilidad entre y en Estados miembros, en tanto que puede constituir una línea de desarrollo del modelo de securitización de la Unión Europea.

El objetivo de este texto en doble: por un lado pretende ser un estudio exploratorio de una temática desatendida, como son las fronteras internas de la UE, poniendo el foco en una realidad jurídica desconocida como es la frontera entre España y Francia, y mirando tanto a los propios contextos fronterizos y las regulaciones que sobre ellos existen, así como a las cifras de personas readmitidas en virtud del Acuerdo de Readmisión de 2002; Y, en segundo lugar, se trataría la cuestión de la (no) garantía de derechos de las personas readmitidas, en especial la asistencia jurídica por parte de letrados de los Turnos de Extranjería de los Colegios de Abogados. En caso de la frontera Irun-Hendaia es un ejemplo paradigmático de dichas prácticas policiales transfronterizas.

\section{Fronteras interiores en la "Europa sin}

fronteras"

Desde la conformación del Acuerdo de Schengen en $1985^{3}$, así como su Convenio de aplicación de 19 de junio de 1990, una de las principales aspiraciones de la Unión Europea ha sido la denominada "supresión progresiva de controles en fronteras comunes". Aún así, las reticencias de los Estados a ceder competencias en materia de control de fronteras también han sido una constante, como quedó de manifiesto con la aprobación del Acta Única en 1986, excluyendo las materias de control de fronteras del pilar comunitario, y manteniéndolas en el ámbito intergubernamental. No fue hasta el Tratado de Ámsterdam 1999 que se consideró el Acuerdo de Schengen como Derecho comunitario. En la actualidad, la comunitarización del Tercer Pilar por el Tratado de Lisboa de 2007 (o "lisbonización") implica que la totalidad de la regulación en materia de fronteras interiores, cooperación policial y judicial sean materia de codecisión. En este sentido, tanto el artículo 67.2 como el 77 del Tratado de Funcionamiento de la UE reiteran la garantía de ausencia de controles de las personas, sea cual sea su nacionalidad, en

\footnotetext{
3 Acuerdo entre los Gobiernos de los Estados de la Unión Económica del Benelux, la República Federal de Alemania y la República Francesa relativo a la supresión gradual de los controles en las fronteras comunes

4 http://www.europarl.europa.eu/eplibrary/Schengen-governanceafter-the-Lisbon-Treaty.pdf
} 


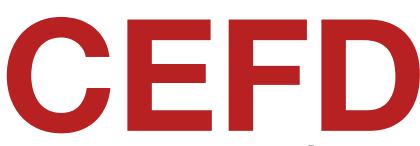

Cuadernos Electrónicos de Filosofía del Derecho

las fronteras interiores. Concretamente, el Código de normas de la Unión para el cruce de personas por las fronteras, o Código de fronteras Schengen $(\mathrm{CFS})^{5}$, en su artículo primero, al referirse al "Objeto y principios", menciona expresamente "la ausencia de controles fronterizos de las personas que crucen las fronteras interiores de los Estados miembros de la Unión Europea"; refiriéndose a estas fronteras interiores como "las fronteras terrestres comunes, a los aeropuertos si se trata de vuelos interiores $\mathrm{y}$ puertos si son enlaces interiores regulares". Esté código, establece que “(L)as fronteras interiores podrán cruzarse en cualquier lugar sin que se realice inspección fronteriza alguna de las personas, cualquiera que sea su nacionalidad" (Artículo 22).

Recientemente, en el documento de la Comisión Europea denominado Restablecer Schengen Hoja de ruta COM(2016) 120 final, se afirma que “(E)1 restablecimiento continuado de los controles en las fronteras interiores en la UE no resolvería los problemas planteados por la crisis migratoria $\mathrm{y}$, sin embargo, acarrearía enormes costes económicos, políticos y sociales

\footnotetext{
${ }^{5}$ Reglamento (CE) n. ${ }^{\circ}$ 562/2006 del Parlamento Europeo y del Consejo, de 15 de marzo de 2006, por el que se establece un Código comunitario de normas para el cruce de personas por las fronteras (Código de fronteras Schengen) (DO 2006, L 105, p. 1), en su versión modificada por el Reglamento (UE) n. ${ }^{\circ}$ 610/2013 del Parlamento Europeo y del Consejo, de 26 de junio de 2013 (DO 2013, L 182, p. 1) (en lo sucesivo, «Reglamento n. ${ }^{\circ}$ 562/2006»). Y por el ${ }^{5}$ Reglamento (UE) 2016/399 del Parlamento Europeo y del Consejo de 9 de marzo de 2016.
}

para la UE y los distintos Estados miembros. Además, pondría en peligro la cooperación policial y judicial que se ha convertido en uno de los elementos clave del valor añadido del sistema de Schengen”.

Precisamente, frente a un proceso de eliminación gradual de las fronteras interiores, el sistema Schengen ha habilitado la implementación de una serie de "medidas compensatorias" como el Eurodac, el Sistema de Información Schengen I y II, así como un fuerte compromiso con la cooperación policial transfronteriza, a la que hacía referencia la Comisión Europea, con el fin de combatir al mismo tiempo la movilidad migratoria y la criminalidad (Van der Woude y Van Berlo 2015). En esta línea, de conformidad con el art 23 del CFS (y en consonancia con la redacción del artículo 72 TFUE), la ausencia de controles en las fronteras interiores no afectaría al ejercicio de las competencias de policía de las autoridades competentes de los Estados miembros en virtud de su Derecho interno (en cuanto al mantenimiento del orden público y la salvaguardia de la seguridad interior), en la medida en que el ejercicio de tales competencias no tenga un efecto equivalente a las inspecciones fronterizas. Este articulado habilitaría la realización de "inspecciones aleatorias, sin la necesaria comunicación previa a ninguna autoridad comunitaria, dentro del territorio $\mathrm{y}$ zona fronteriza $\sin$ efecto equivalente a las 
Cuadernos Electrónicos de Filosofía del Derecho

inspecciones fronterizas, basadas en información y experiencia policiales de carácter general sobre posibles amenazas a la seguridad pública $\mathrm{y}$ destinadas, en particular, a combatir la delincuencia transfronteriza, y relacionadas con la obligación de llevar consigo documentos de extranjería".

En este sentido ha versado la jurisprudencia TJUE, ya sea en el asunto Melki y Abdeli C188/10 y C-189/10, el asunto Adil C-278/12 (Mangas 2012), así como el asunto resuelto el 21 de junio de 2017, una cuestión prejudicial (C9/16), planteada por el Juzgado de Distrito Kehl (Alemania) el 7 de enero de 2016, sobre la facultad de identificar a cualquier persona, con independencia de su comportamiento y de la existencia de circunstancias especiales, en una zona de $30 \mathrm{~km}$ desde la frontera terrestre o en estaciones de ferrocarril. En este último fallo, y en la líneas de las anteriores, el TJUE ha estimado que una normativa estatal que confiera a la policía la competencia para controlar la identidad de cualquier persona en una zona de 30 kilómetros a partir de la frontera terrestre de ese Estado miembro con otros Estados miembros con el fin de prevenir o poner fin a la entrada o residencia ilegales en el territorio de dicho Estado miembro o de prevenir determinados delitos contra la seguridad de las fronteras, con independencia del comportamiento de la persona de que se trate y de la existencia de circunstancias particulares, es contraria al acervo comunitario, "salvo que tal normativa establezca la necesaria delimitación de esta competencia que garantice que el ejercicio en la práctica de para que no tenga un efecto equivalente al de las inspecciones fronterizas". Sin embargo, el Tribunal estima que no es contrario al acervo comunitario "una normativa nacional que permita que los servicios de policía del Estado miembro efectúen, a bordo de los trenes $o$ en el recinto de las instalaciones ferroviarias de ese Estado miembro, controles de identidad de cualquier persona o de los documentos que permiten cruzar la frontera, y puedan dar el alto e interrogar a cualquier persona a tal fin, cuando esos controles se basan en el conocimiento de la situación o en la experiencia de la policía fronteriza, siempre que el ejercicio de tales controles quede sujeto en el Derecho nacional a precisiones y limitaciones que determinen la intensidad, la frecuencia y el carácter selectivo de tales controles, extremo que incumbe comprobar al órgano jurisdiccional remitente".

Los artículos 25 y siguientes del Reglamento Schengen recogen como mecanismo posible el "restablecimiento temporal de controles fronterizos en las fronteras interiores" con el fin de "responder correctamente a la amenaza para el orden público o la seguridad interior", “en fronteras específicas o en la totalidad", "con 


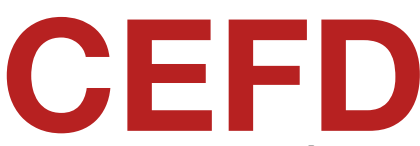

Cuadernos Electrónicos de Filosofía del Derecho

carácter excepcional" y "durante un período de tiempo limitado no superior a 30 días". Además, con arreglo al artículo 29 del Código de fronteras Schengen, la Comisión puede proponer una recomendación, que deberá adoptar el Consejo por mayoría cualificada, para restablecer los controles en la totalidad o en determinadas partes de la frontera de uno o más Estados miembros como último recurso. Los controles pueden establecerse durante un periodo máximo de seis meses, y pueden prolongarse por periodos adicionales de seis meses hasta un máximo de dos años. En este acto, el Consejo podrá recomendar que uno o más Estados miembros decidan restablecer los controles fronterizos en todas sus fronteras interiores o en partes concretas de ellas.

Aún así, a pesar de que el mecanismo previsto para la reintroducción de las fronteras internas requiere de supervisión del Consejo y la Comisión, como ha señalado Olesti Rayo, las instituciones comunitarias "apenas han ejercido un control sobre la necesidad y la oportunidad del restablecimiento de las inspecciones fronterizas" (2012:82), lo que ha derivado en la acción unilateral de los Estados. De hecho, es importante ver la evolución cuantitativa que ha experimentado este mecanismo. Si entre 2006 y 2014 fue empleado 35 veces (por Francia con motivo de las Jornadas de la izquierda abertzale en Senpere-Baiona en octubre 2006; por Alemania en mayo y junio de 2007 con motivo de la cumbre del G8; por Noruega con motivo de la ceremonia del Premio Nobel en Oslo en noviembre-diciembre de 2009; etc); entre 2015 y mayo de 2017 (apenas dos años) se ha aplicado 38 veces $^{6}$. Los motivos principales alegados por Francia han sido el Estado de emergencia decretado como consecuencia de los atentados terroristas. Por su parte, Noruega, Suecia, Dinamarca Alemania, Austria, Francia, Malta, Hungría han alegado los denominados "movimientos secundarios no autorizados" $"$. En este contexto último, el Consejo y la Comisión han optado por renovar, una última vez, 3 meses más los controles fronterizos temporales, recomendando optar por los controles policiales de identidad en zonas fronterizas. Así, el Consejo en la reciente Decisión de Ejecución (UE) 2017/246, de 7 de febrero ${ }^{8}$, anima explícitamente a los Estados miembros a evaluar si, "ante una previsión de una nueva reducción de los flujos migratorios "con los controles policiales no se

\footnotetext{
6 https://ec.europa.eu/home-affairs/sites/homeaffairs/files/whatwe-do/policies/borders-and-visas/schengen/reintroduction-bordercontrol/docs/ms_notifications_-

_reintroduction_of_border_control_en.pdf

${ }^{7}$ Decisiones del Consejo: 12 May 2012, 11 Nov 2016, 7 Feb 2017. Es importante señalar la advertencia del Consejo de que la de mayo será la última renovación.

8 Decisión de Ejecución (UE) 2017/246 del Consejo, de 7 de febrero de 2017, por la que se establece una Recomendación para prorrogar la realización de controles temporales en las fronteras interiores en circunstancias excepcionales que pongan en peligro el funcionamiento global del espacio Schengen
} 
Cuadernos Electrónicos de Filosofía del Derecho

lograrían los mismos resultados que con los controles temporales en las fronteras interiores, antes de introducir o prorrogar estos últimos. En la misma línea se ha pronunciado la Comisión Europea a través de la Recomendación (UE) 2017/820, de 12 de mayo de 2017, "sobre los controles policiales proporcionados y la cooperación policial en el espacio Schengen". Según la Comisión "dichos controles pueden resultar más eficaces que los controles en las fronteras interiores, sobre todo porque son más flexibles que los controles fronterizos estáticos en pasos fronterizos específicos y pueden adaptarse más fácilmente a la evolución de los riesgos”. También dice que "(L)as patrullas policiales conjuntas $\mathrm{y}$ otros instrumentos existentes de cooperación policial operativa contribuyen a la seguridad interior en el espacio sin controles en las fronteras interiores. Las patrullas conjuntas a bordo de trenes transfronterizos, por ejemplo, claramente mejoran la seguridad, al prevenir situaciones en las que la falta de simetría en los controles debilita los esfuerzos realizados a un lado de la frontera únicamente". Por último, en esta decisión, el Comisario Dimitris Avramópulos fomenta un " uso eficaz de los acuerdos o acuerdos bilaterales de readmisión entre los Estados miembros para garantizar que los controles policiales y la cooperación policial puedan conducir a la represión efectiva de los movimientos secundarios no autorizados cuando dichos movimientos supongan una amenaza específica para las políticas públicas de seguridad interior".

Por tanto, cuando se trata de controles sistemáticos, reiterativos e intensivos en una zona fronteriza específica, aunque no haya un reestablecimeinto formal de las fronteras interiores ¿No estaríamos controles fronterizos disfrazados de controles de identidad? ¿Supondría un reestablecimiento de facto de las fronteras interiores sin el procedimiento preceptivo? Lo que sí es evidente, es que un elemento fundamental en la delimitación e implementación de este tipo de controles, como veremos más adelante, son los amplios márgenes de discrecionalidad derivados de las "zonas grises" (Van der Woude y Van der Leun 2017) que recorren la normativa sobre controles en zonas fronterizas, tanto comunitaria como estatal.

3. Descripción de la zona fronteriza IrunHendaia y los controles policiales

La frontera entre los Estados español y francés se extiende algo más de 656 kilómetros, a lo largo de la cordillera de los Pirineos desde el Mar cantábrico hasta el Mediterráneo. La delimitación fronteriza contemporánea proviene de los denominados Tratados de Bayona, firmados entre 
Cuadernos Electrónicos de Filosofía del Derecho

1856 y 1868, durante los reinados de la reina de España, Isabel II y del emperador francés Napoleón III. Concretamente, fueron sucesivos los tratados que establecieron las fronteras en base a las provincias del lado español (Tratado de 1856, las provincias de Gipuzkoa y Navarra; Tratado de 1862, las provincias de Huesca y Lleida; y finalmente, el Tratado de 1866, valle de Andorra hasta el Mediterráneo). Como dice Lafourcade, históricamente ha sido un espacio de "conflictos interestatales y de colaboración interregional" (1998).

Actualmente, cuenta con 23 pasos fronterizos siendo los más importantes los de Irun-Hendaia y Jonquera-Le Perthus.. Según el Observatorio hispano-francés de Tráfico en los Pirineos (2016), estos pasos soportaron en 2014 el 38\% del tráfico ligero $(12,58$ y 17,7 millones de viajeros respectivamente) y el 59\% de autocares (1,43 y 1,95 millones de viajeros). Además hay 6 líneas ferroviarias transfronterizas, que fueron empleadas por 1.6 millones de personas en 2014. La regulación genérica de estas zonas fronterizas se remonta a años atrás, al Convenio entre España y Francia, relativo a las Oficinas de Controles Nacionales Yuxtapuestos y de Controles en ruta, de 7 de julio de 1965, por medio del cual se establecen los parámetros principales en lo que refiere a establecimiento de oficinas fronterizas, realización de controles, régimen jurídico de los funcionarios y cooperación conjunta. En virtud de estos acuerdos (y de la distribución competencial según el Derecho interno), las policías competentes para el control de extranjería en la zona son, por parte del Estado francés, los agentes adscritos a la Comisaría la Policía del Aire y de las Fronteras; y los agentes de la Brigada de Extranjería y Fronteras de la Policía Nacional, por parte del Estado español.

La zona fronteriza Irun-Hendaia (en la parte oeste/atlántica del Pirineo) concretamente son 3 puntos de paso: Santiago, Pausu y Biriatou, todos ellos por encima del río Bidasoa. El paso de Santiago, el más antiguo, (y símbolo de la huida de los refugiados vascos hacia Francia en la Guerra Civil española en 1937) lo cruzan cuatro puentes: la línea ferroviaria internacional MadridHendaia; la línea cercanías San SebastianHendaya (el Topo); el tercero es un puente peatonal; y el cuarto puente es el puente Santiago para peatones y tráfico rodado. Los principales puntos para la realización de controles policiales por parte de policías francesas y españolas, son el propio puente Santiago, así como sus inmediaciones (Ficoba); y las estaciones de tren de Irun y de Hendaia. A escasos 100 metros del puente Santiago, en el lado francés, se sitúa el complejo arquitectónico policial que ubica la Comisaría de la Policía del Aire y Fronteras, el Centro de Coordinación Policial y Aduanas Hispano-Frances, sobre el que hablaremos 


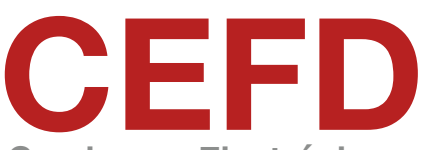

Cuadernos Electrónicos de Filosofía del Derecho

después, y el Centre de Retention Administrative.

En este centro, según la organización francesa CIMADE, quien tiene asignada la asistencia jurídica a los internos, de las 320 personas recluidas en 2015, 207 (73\%) fueron arrestadas directamente en la frontera ${ }^{9}$. El puente de Pausu (ubicado en el término municipal de Urruña) también es lugar de controles por policía de ambos Estados, y generalmente es la mitad del puente la que delimita la ubicación de cada uno de los controles. La zona fronteriza de la “Estructura binacional de Biriatou”, que está situada entorno al peaje de la autopista AP-8/A63, reemplazó a los puestos fronterizos de ambos estados. De hecho, la ubicación y arquitectura de este peaje está muy influenciada por el contexto fronterizo en que se localiza, como si de un puesto de control fronterizo camuflado se tratara: cámaras de vigilancia, garitas para agentes, oficinas de extranjería a ambos lados, etc (en Le Perthus-La Jonquera, a día de hoy también se sigue sin desmantelar la arquitectura fronteriza anterior). Esta zona de Biriatou está jurídicamente delimitada por el Canje de Notas hispano-francés, de julio de 1967, relativo a la creación en Biriatou, territorio francés, de la oficina de controles yuxtapuestos. El área entre el río Bidasoa y el peaje, pese a ser territorio francés, se

\footnotetext{
9 http://www.lacimade.org/publication/rapport-2015-sur-centre-etlocaux-de-retention-administrative/ . Entre 2016 y 2017 el centro permanece cerrado a efectos de personas internadas.
}

denomina Zona de Yuxtaposición, donde se ubica la Oficina española de Policías, y donde se suelen realizar los controles. Al otro lado del peaje se localizan las oficinas de la policía y aduanas francesas.

Si bien es imposible dar una cifra oficial de controles efectuados en la zona fronteriza, si podemos decir que la policía francesa, especialmente desde la declaración de estado de emergencia, ha situado sus efectivos de puntual en los puentes Santiago y Pausu, y manera permanente en la frontera de Biriatou. La Policía Nacional española, por su parte, según la Consejería Vasca de Interior, en 2016, únicamente comunicó tres controles. Sin embargo, es una constatne para la población transfronteriza. Un oficial de policía, en declaraciones a un medio de comunicación a raíz de los controles franceses, decía que "(S)omos sólo entre cuatro y ocho personas por turno (....) Si pasan 50 autobuses al día sólo se miran cinco. Desde mediados de 2015, estos mismos agentes tienen también que hacer «patrullas mixtas» con colegas franceses en los trenes transfronterizos desde Baiona hasta San Sebastián” (El Mundo, 5 de noviembre de 2015). Por tanto, la ausencia de controles oficiales no debe confundirse con el control diario de personas o de vehículos, ni con las "patrullas mixtas" en ambos territorios. 
Cuadernos Electrónicos de Filosofía del Derecho

Es necesario resaltar la evolución de la cooperación transfronteriza, especialmente en materia de control de la inmigración. Si bien los convenios de 1965 y 1976 ya hacían alguna mención a acciones de apoyo y trabajo conjunto entre agentes fronterizos de ambos Estados, es el Convenio de Cooperación Transfronteriza en materia Policial y Aduanera entre España Francia, firmado en Blois el 7 de julio de 1998, el que sin duda marca definitivamente la agenda de la cooperación policial transfronteriza. Francia tiene acuerdos similares con sus países vecinos como Alemania (9 de octubre de 1997), Bélgica (5 de marzo de 2001), Italia (3 de octubre de 1997), Luxemburgo (15 de octubre de 2001) y Suiza (9 de octubre de 2007). España, por su parte, también tiene un acuerdo de estas características con Portugal (19 de noviembre de 2005).

Uno de los principales productos del Convenio de Blois son los centros de cooperación policial y aduanera (CCPA) encargados principalmente "de luchar contra la inmigración irregular, la delincuencia fronteriza, la prevención de las amenazas contra el orden público y los tráficos ilícitos" (art. 5), "la preparación y entrega de extranjeros en situación irregular en las condiciones previstas por el Acuerdo hispanofrancés de admisión en puestos fronterizos de personas en situación de estancia ilegal, la ayuda para la preparación y el apoyo de las vigilancias y; la coordinación de medidas conjuntas de vigilancia en la zona fronteriza" (art 7), "coordinar sus acciones comunes en la zona fronteriza, en particular para luchar contra la delincuencia fronteriza y prevenir las amenazas contra la seguridad y el orden público; así como recoger e intercambiar información en materia policial y aduanera" (art. 10).

En virtud de este acuerdo se han creado cuatro centros: Hendaia, Melles y La Perthus en Francia; y Canfranc, en territorio Español. En el CCPA de Hendaia, ubicado como decíamos en las inmediaciones del paso fronterizo de Santiago, fue creado en 2004, aunque llevan trabajando de manera conjunta desde 1997 en la oficina de Biriatou. Es el único abierto 24 horas, y en él trabajan cerca de 64 agentes de distintos cuerpos policiales: Policía nacional francesa, Gendarmería, Aduanas francesas, Policial Nacional española, Guardia Civil, Policía Autonómica Vasca Ertzaintza y Agencia Tributaria Española. Las principales labores que realiza concretamente este centro es la puesta en común de información de las respectivas bases de datos (SIS, Eurodac, Adexttra, Argos...) y la coordinación entre cuerpos policiales para la realización de acciones policiales como incursiones de agentes de un Estado en el otro, la patrullas conjuntas en medios de transporte y las entregas de personas detenidas con el objeto de ser readmitidas por el otro Estado. 
entre España y Francia, firmado en Málaga el 26 de noviembre de 2002, y con fecha de entrada en

\section{La readmisión de detenidos}

La readmisión de extranjeros detenidos por estancia irregular ha sido uno de los pilares de la política de control de fronteras de la UE y sus Estados Miembros desde por lo menos el Consejo Europeo de Sevilla de junio de 2002 (Comisión Europea $2002^{10}$ ). Sin embargo, estos acuerdos han sido analizados con profundidad en su vertiente externa, es decir, con terceros Estados, y no entre Estados miembro (Schieffer 2003 o Strik 2010). En este sentido, el caso que nos ocupa puede ser un buen punto de partida para en un futuro abrir vías metodológicas de y debate de cara a analizar otros casos similares como el Convenio entre España y Portugal relativo a la readmisión de personas en situación irregular, hecho en Granada el 15 de febrero de 1993; o el Acuerdo entre el Gobierno de la República Federal de Alemania y el Gobierno de la República Francesa relativo a la readmisión y el tránsito de los inmigrantes ilegales, firmado el 10 de febrero de 2003.

Concretamente vamos a analizar el Acuerdo sobre la readmisión de personas en situación irregular

10 European Commission (2002), Communication from the Commission to the Council and the European Parliament on a Communit y Return Policy on Illegal Residents , COM (2002) 504 final. vigor el 21 de diciembre de $2003^{11}$. En cuanto a su contenido, debemos comenzar por el objeto que es tanto para la readmisión de nacionales de los países firmantes (art 1 y ss), así como de nacionales de terceros países arrestados en uno de los países firmantes y procedentes del otro país firmante (art 5 y ss). Respecto a estos últimos, el artículo 6 establece algunas excepciones al determinar que “(N)o existirá la obligación de readmisión" cuando a) los readmitidos provengan de países con frontera común con el Estado que realiza la readmisión activa; b) que ya cuenten con visado o permiso de residencia en el Estado requirente; c) los que residan desde hace más de 6 meses en el Estado requeriente; d) el Estado requeriente les haya reconocido el estatuto de refugiado; e) o sea el encargado del primer examen de la solicitud de asilo; f) los que ya fueron expulsados por el Estado requerido; y g) los que cuenten con un permiso provisional de algún Estado Schengen.

La parte tercera (art 10 a 21) refiere al "Tránsito para la expulsión o transito subsiguiente a la decisión de denegación de entrada en el Territorio", especialmente en lo que respecta a los

\footnotetext{
${ }^{11}$ En Francia fue traspuesto a través del Decreto $N^{\circ}$ 2004-226 de 9 de marzo de 2004 sobre la publicación del Acuerdo entre la República Francesa y el Reino de España sobre la readmisión de inmigrantes ilegales firmados en Málaga el 26 de noviembre de 2002, entró en vigor el 21 de diciembre 2003.
} 
Cuadernos Electrónicos de Filosofía del Derecho

agentes de escolta y su identificación, las condiciones de armamento reglamentario, las situaciones en que la personas readmitida cometa infracciones, así como los gastos generados del tránsito. En todo caso, el plazo genérico para responder a las solicitudes es "solicitud lo antes posible" aunque se dice genéricamente que pueden ser "48 horas, prorrogables 24 horas más". Este plazo de 3 días es lógico, al menos para el ordenamiento español puesto que la Constitución española marca el plazo de 72 horas para la detención sin intervención judicial.

El apartado cuarto se refiere a la "Protección de datos personales", siendo estos "datos personales relativos a la persona que vaya a ser readmitida o expulsada y, eventualmente, los de sus familiares (apellidos, nombre, nombre anterior, en su caso, sobrenombres o seudónimos, lugar y fecha de nacimiento, sexo, nacionalidad); el documento de identidad, el pasaporte o los demás documentos de identidad o de viaje; los demás datos necesarios para identificar a la persona que vaya a ser readmitida o expulsada; los lugares de estancia y los itinerarios; las autorizaciones de residencia o los visados concedidos en el extranjero" (art 23), y limitándose el uso de estos datos a los solos efectos de la readmisión.

En la parte última (V. Disposiciones generales y finales), remite al anexo sobre los detalles de aplicación así como "los aeropuertos y los puestos fronterizos terrestres que podrán utilizarse para la readmisión y los aeropuertos de entrada en tránsito de los extranjeros (Anexo. 5); las autoridades centrales o locales facultadas para conocer de las solicitudes de readmisión y de tránsito así como los problemas jurídicos (anexo 6); "los plazos para la tramitación de las solicitudes"; los funcionarios competentes para componer las escoltas" (anexo. 7); y las lenguas de comunicación (las oficiales en cada Estado solicitante). Al final se incluyen una serie de formularios tipo par la "Solicitud de readmisión de un Solicitud de tránsito para la expulsión de nacional de la otra parte contratante" "de un nacional de tercer estado" o de "de tránsito para la expulsión de uno o varios extranjeros".

En 2013, en el contexto la IV reunión del Comité de Planificación y Coordinación Estratégica de Seguridad Interior Hispano Francés celebrado en Salamanca, se firmó un acuerdo técnico para la readmisión por vía aérea de personas en situación irregular. Este acuerdo técnico establece la Unidad Central de Fronteras de la Comisaría General de Extranjería y Frontreras de la Policía Nacional como única autoridad en España con capacidad para decidir sobre las solicitudes de admisión. En el caso de Francia será la Direction Centrale de la Police Aux Frontières la responsable única de tramitar estos procesos. Este convenio técnico mantiene nueve aeropuertos 
Cuadernos Electrónicos de Filosofía del Derecho

como puntos de entrega de readmitidos, cinco en territorio francés (Paris- Charles de Gaulle, ParisOrly, Lyón-Saint Exupéry, Marsella-Provence y Toulouse-Blagnac), y cuatro en territorio español (Madrid-Barajas, Barcelona-El Prat, ValenciaManises, Málaga-San Julián). Así mismo, parece que se suprime la readmisión inmediata en frontera, establecida para nacionales de terceros países, dentro de las cuatro horas posteriores al paso ilegal de frontera común, aunque en la práctica, como veremos, no se ha constatado tal cambio.

En virtud de este acuerdo, entre 2003 y 2015, y según el Ministerio de Interior español, más de 300.000 personas han sido objeto de readmisión entre las partes firmantes. Específicamente Francia ha enviado 54.053 personas hacia España, mientra que ésta ha enviado hacia Francia 251.898. Ahora bien, es importante realizar un análisis interanual y por nacionalidades para tener una visión real de la magnitud de los datos.

Respecto a las readmisiones que España ha realizado hacia Francia, es decir, de personas que realizaban la ruta norte-sur, lo primero que llama la atención son las readmisiones de ciudadanos de países de Europa del Este, entre 2003 y 2006, cuya explicación es que durante aquellos años estas nacionalidades aún era extracomunitarios, y por tanto precisaban de permiso o visado para en cualquier Estado Miembro. Es también importante resaltar que entre 2004 y 2005 se produjeron diversos procesos extraordinarios de regularización, lo que motivó diversos desplazamientos hacia el territorio español. Tal y como declaró el Ministro del Interior ante la Comisión de Interior del Congreso de los Diputados en fecha 17 de mayo de 2005 (Diario de Sesiones del Congreso de los Diputados $\mathrm{n}^{\circ}$ 278), en 2004 se dio un incremento importante de las plantillas de la policía y guardia civil en frontera pirenaica así como en el aeropuerto de Barajas (147 nuevos puestos dedicados específicamente a potenciar el control de fronteras: 12 en Portbou, 22 en La Junquera, 10 en Canfranc, 8 en Irun y 95 en Barajas): "Estas actuaciones en materia de efectivos han posibilitado que el reciente proceso extraordinario de normalización se haya desarrollado en un marco adecuado de control de fronteras, sobre cuya eficacia es bastante elocuente el importante incremento que ha experimentado el número de readmisiones. Lo estamos reforzando, lo hemos reforzado y lo seguimos reforzando". En todo caso, que en 2003, año de entrada en vigor del acuerdo (21 de diciembre de 2003), se realizaran 50.407 readmisiones es un dato importante. También se aprecia un continuado descenso interanual que parece estabilizarse en los últimos años en la cifra de las 1000 readmisiones. Pueden llamar la atención nacionalidades como 


\section{CEFD}

Cuadernos Electrónicos de Filosofía del Derecho

Marruecos o Argelia, y esto es debido a la ruta habitual que enlaza Europa con sus países de origen (especialmente en períodos vacacionales). Es interesante que según el anteriormente citado artículo 6 a), no existe obligación por parte de Francia de readmitir nacionales de Maruecos, por ejemplo, puesto que España sí cuenta con una frontera común.

Tabla 2: Readmisiones de España hacia Francia (Total)

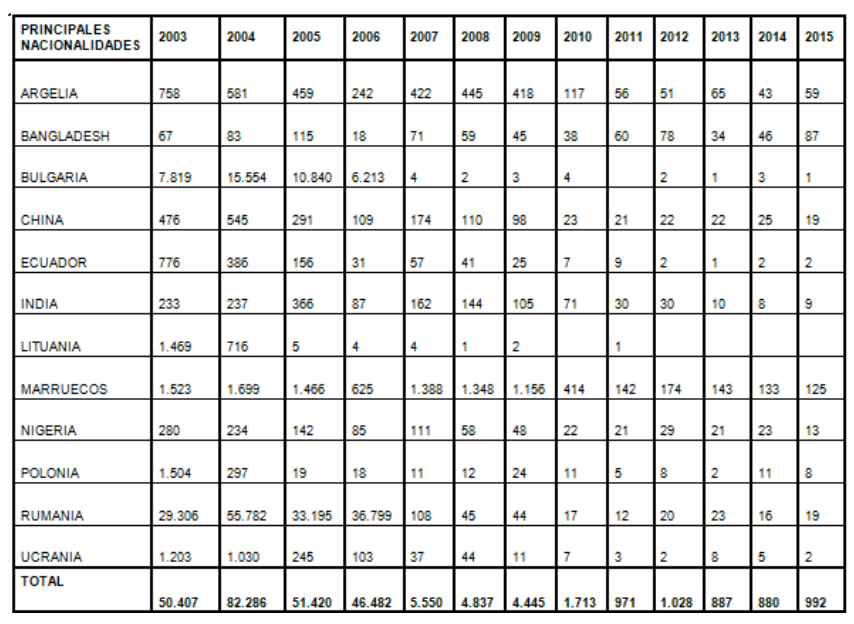

Fuente: Ministerio de Interior (Portal de Transparencia)

Francia, por su parte, ha readmitido hacia España, es decir, personas que hacían la ruta sur-norte, un número que oscila entre las 3000 y 6000 personas. Marruecos y Argelia, de nuevo, son las nacionalidades más reseñables, aunque otras nacionalidades africanas como Senegal, Mali Pakistan o India también son relevantes. Y finalmente, es de resaltar la importante presencia se personas procedentes de Siria, lo que pone de manifiesto la readmisión-deportación de "potenciales refugiados" que intentan llegar a países como Reino Unido o Alemania vía la frontera sur (tras la estancia en Ceuta o Melilla).

\section{Tabla 3: Readmisiones de Francia hacia}

\section{España (Total)}

\begin{tabular}{|l|l|l|l|l|l|l|l|l|l|l|l|l|}
\hline \begin{tabular}{|l} 
PRINCIPALES \\
NACIONALIIDADS
\end{tabular} & 2004 & 2005 & 2006 & 2007 & 2008 & 2009 & 2010 & 2011 & 2012 & 2013 & 2014 & 2015 \\
\hline ARGELIA & 228 & 269 & 190 & 202 & 286 & 326 & 331 & 280 & 315 & 283 & 245 & 262 \\
\hline BOLIVIA & 23 & 24 & 66 & 100 & 112 & 152 & 147 & 127 & 158 & 93 & 103 & 130 \\
\hline COLOMBIA & 46 & 60 & 68 & 61 & 111 & 141 & 203 & 205 & 190 & 181 & 126 & 128 \\
\hline ECUADOR & 136 & 116 & 96 & 91 & 143 & 160 & 212 & 241 & 188 & 138 & 110 & 162 \\
\hline MALI & 74 & 59 & 45 & 37 & 51 & 56 & 70 & 90 & 217 & 270 & 185 & 75 \\
\hline MARRUECOS & 842 & 1.298 & 904 & 1.075 & 1.055 & 1.300 & 1.403 & 1.816 & 1.985 & 1.713 & 1.506 & 1.359 \\
\hline PAKISTAN & 173 & 236 & 109 & 141 & 161 & 207 & 161 & 222 & 279 & 182 & 181 & 152 \\
\hline RUMANIA & 365 & 819 & 1.847 & 14 & 18 & 16 & 27 & 35 & 28 & 23 & 27 & 38 \\
\hline SENEGAL & 71 & 48 & 83 & 89 & 96 & 121 & 108 & 173 & 201 & 186 & 212 & 187 \\
\hline SIRIA & 4 & 2 & 10 & 3 & 3 & 5 & 4 & 6 & 38 & 42 & 180 & 227 \\
\hline TOTALES & 3.246 & 4.625 & 4.711 & 3.404 & 3.648 & 4.264 & 4.319 & 5.214 & 6.103 & 5.066 & 4.868 & 4.585 \\
\hline
\end{tabular}

Fuente: Ministerio de Interior (Portal de Transparencia)

La frontera occidental de Irun-Hendaia, si bien no es la más transitada por personas y vehículos (frente a La Jonquera-Le Perthus), una media anual de 1.500 personas han sido readmitidas en los últimos 5 años. Las tasas de readmisión que la Policía española ha arrestado en su lado de la frontera y enviado a Francia, rondan el 50\% aproximadamente del total de toda la frontera. Es 


\section{CEFD}

Cuadernos Electrónicos

de Filosofía del Derecho

cierto que entre 2003 y 2007, aquellas

nacionalidades europeas extracomunitarias, por

cercanía accedían principalmente sobre todo por

la Jonquera-Le Perthus, no obstante, como

veremos más adelante, algunos de estos casos

feron polémicos judicialmente por la manera en que se realizan estas readmisiones. Es interesante ver cómo en 2003 se produjeron 1762 readmisiones con la entrada en vigor del acuerdo. Además, es de destacar que en los últimos 5 años las readmisiones o se mantienen o se incrementan, a diferencia del cómputo global que desciende sensiblemente. Dicho de otra manera, la frontera Irun-Hendaia mantiene un ritmo importante de detenciones en el lado sur.

\section{Tabla 4: Readmisiones de España hacia Francia (Frontera Irun-Hendaia)}

\begin{tabular}{|l|l|l|l|l|l|l|l|l|l|l|l|l|l|}
\hline $\begin{array}{l}\text { PRINCIPALES } \\
\text { NACIONALIDADES }\end{array}$ & $\mathbf{2 0 0 3}$ & $\mathbf{2 0 0 4}$ & $\mathbf{2 0 0 5}$ & $\mathbf{2 0 0 6}$ & $\mathbf{2 0 0 7}$ & $\mathbf{2 0 0 8}$ & $\mathbf{2 0 0 9}$ & $\mathbf{2 0 1 0}$ & $\mathbf{2 0 1 1}$ & $\mathbf{2 0 1 2}$ & $\mathbf{2 0 1 3}$ & $\mathbf{2 0 1 4}$ & $\mathbf{2 0 1 5}$ \\
\hline ARGELIA & 50 & 31 & 42 & 13 & 49 & 22 & 14 & 6 & 9 & 18 & 21 & 14 & 18 \\
\hline BANGLADESH & 24 & 13 & 58 & 7 & 31 & 26 & 32 & 19 & 47 & 40 & 30 & 45 & 84 \\
\hline BRASIL & 40 & 81 & 107 & 45 & 145 & 55 & 31 & 3 & 13 & 15 & 18 & 11 & 10 \\
\hline CHINA & 124 & 97 & 51 & 10 & 71 & 23 & 9 & 7 & 8 & 10 & 14 & 18 & 13 \\
\hline INDIA & 59 & 35 & 137 & 5 & 32 & 19 & 6 & 4 & 2 & 1 & 2 & 6 & 6 \\
\hline MARRUECOS & 129 & 120 & 120 & 54 & 240 & 73 & 44 & 20 & 33 & 65 & 69 & 55 & 48 \\
\hline PAKISTAN & 36 & 35 & 317 & 10 & 23 & 9 & 7 & 6 & 13 & 8 & 8 & 12 & 26 \\
\hline RUMANIA & 303 & 439 & 1.613 & 1.952 & & 4 & & & & & & & \\
\hline TOTAL & $\mathbf{1 . 7 6 2}$ & $\mathbf{1 . 4 7 6}$ & $\mathbf{3 . 0 2 2}$ & $\mathbf{2 . 2 6 3}$ & $\mathbf{1 . 2 2 4}$ & $\mathbf{5 5 1}$ & $\mathbf{3 2 9}$ & $\mathbf{1 4 5}$ & $\mathbf{2 5 4}$ & $\mathbf{3 0 4}$ & $\mathbf{3 9 8}$ & $\mathbf{3 8 6}$ & $\mathbf{3 9 9}$ \\
\hline
\end{tabular}

Fuente: Ministerio de Interior (Portal de Transparencia)

Por el contrario, el porcentaje de readmisiones que Francia ejecuta formalmente hacia España, en la frontera de Irun-Hendaia rondan el 25\% del total fronterizo, experimentando un ligero descenso. Destacan, al igual que en la tabla del total de la frontera, Marruecos y Argelia, así como otras nacionalidades como Camerún o Pakistán, y las latinoamericanas como Ecuador, Colombia o Brasil. Llama también aquí la atención el incremento de los últimos años de personas sirias que pretenden cruzar la frontera hacia el norte y que son devueltas.

Tabla 5: Readmisiones de Francia hacia España (Frontera Irun-Hendaia)

\begin{tabular}{|l|l|l|l|l|l|l|l|l|l|l|}
\hline $\begin{array}{l}\text { PRINCIPALES } \\
\text { NACIONALIDADES }\end{array}$ & $\mathbf{2 0 0 4}$ & $\mathbf{2 0 0 7}$ & $\mathbf{2 0 0 8}$ & $\mathbf{2 0 0 9}$ & $\mathbf{2 0 1 0}$ & $\mathbf{2 0 1 1}$ & $\mathbf{2 0 1 2}$ & $\mathbf{2 0 1 3}$ & $\mathbf{2 0 1 4}$ & $\mathbf{2 0 1 5}$ \\
\hline ARGELIA & 46 & 101 & 154 & 167 & 145 & 130 & 135 & 117 & 117 & 87 \\
\hline BRASIL & 10 & 71 & 77 & 55 & 64 & 76 & 67 & 41 & 43 & 19 \\
\hline CAMERUN & 10 & 18 & 21 & 26 & 42 & 55 & 64 & 77 & 111 & 44 \\
\hline COLOMBIA & 9 & 32 & 32 & 46 & 91 & 68 & 47 & 71 & 29 & 18 \\
\hline ECUADOR & 24 & 20 & 40 & 57 & 72 & 99 & 52 & 35 & 17 & 11 \\
\hline MALI & 50 & 21 & 21 & 16 & 31 & 48 & 68 & 98 & 87 & 21 \\
\hline MARRUECOS & 108 & 255 & 201 & 300 & 355 & 391 & 420 & 374 & 314 & 261 \\
\hline PAKISTAN & 58 & 76 & 89 & 84 & 76 & 106 & 71 & 41 & 43 & 18 \\
\hline SIRIA & 2 & 3 & & & & 3 & 20 & 19 & 34 & 67 \\
\hline TOTAL & $\mathbf{7 5 8}$ & 1.403 & $\mathbf{1 . 3 3 0}$ & $\mathbf{1 . 3 9 5}$ & $\mathbf{1 . 5 2 1}$ & $\mathbf{1 . 7 8 9}$ & 1.809 & $\mathbf{1 . 6 0 4}$ & $\mathbf{1 . 3 1 9}$ & $\mathbf{9 3 2}$ \\
\hline
\end{tabular}

Fuente: Ministerio de Interior (Portal de Transparencia)

En definitiva, lo que estos datos nos dicen es que la frontera pirenaica entre los Estados español y francés es una frontera activa donde anualmente entorno a 5.000 o 6.000 personas son formalmente deportadas de un lado a otro. Y la frontera en el País Vasco (Irun-Hendaia) es un punto importante por las cifras de 1.500 personas deportadas, pero sobre todo por la tendencia constante y sensiblemente al alza en los casos de 
Cuadernos Electrónicos

de Filosofía del Derecho

readmisión hacia Francia. En esta línea, lo interesante ahora es ver qué mecanismo de detención y posterior deportación es el que habilita este acuerdo así como el status jurídico que se atribuye técnicamente a estas personas readmitidas, y cuáles son los derechos que se les reconocen.

Es importante resaltar dos ideas principales: la readmisión "sin formalidad alguna" (art 5) y el criterio temporal de "presentación dentro de las cuatro horas posteriores al paso ilegal de la frontera común" (art 7). Para ello, nos centraremos específicamente en el caso español pues han surgido ciertos casos polémicos donde derechos básicos como la asistencia letrada han sido puestos en cuestión. El criterio de la Comisaría de Irun ha sido que el Acuerdo de readmisión prevalece sobre la normativa estatal, esto es, la LO 4/2000, de 11 de enero, sobre derechos y libertades de los extranjeros en España y su integración social y su Reglamento de desarrollo aprobado por Real Decreto 2393/2004; y que no es aplicable la figura de la devolución en aquellos supuestos en los que los extranjeros llegaran a España procedentes de un país integrado en el Acuerdo Schengen y, por lo tanto, la no necesidad de conceder asistencia letrada a los extranjeros que se encuentren en esta situación.

\section{a) Control fronterizo vs control de identidad sistemático}

"Normalmente se controla el tren que hace la ruta

París-Madrid, a las 2 de la mañana. Suelen venir bastantes irregulares" (Conversación con un Policía Nacional español, CCPD).

De la jurisprudencia del TJUE se desprende que los controles realizados en zonas fronterizas únicamente podrían reunir una serie de características (no delimitadas ni normativa ni jurisprudencialmente) que le confirieran un carácter no permanente y aleatorio dentro del territorio y zona fronteriza sin efecto equivalente a las inspecciones fronterizas, basadas en información y experiencia policiales de carácter general sobre posibles amenazas a la seguridad pública y destinadas, en particular, a combatir la delincuencia transfronteriza, y relacionadas con la obligación de llevar consigo documentos de extranjería.

Es cierto también que la actual normativa española de Seguridad Ciudadana ${ }^{12}$, al igual que la anterior, permite cierto control de identidad y documentación. En primer lugar el artículo 13.1 obligaría a los extranjeros a portar consigo la documentación habilitante a residir en el territorio

\footnotetext{
12 Ley Orgánica 4/2015, de 30 de marzo, de protección de la seguridad ciudadana
} 
Cuadernos Electrónicos

de Filosofía del Derecho

español; el artículo 13.3 habilitaría a la policia a la inmovilización de la persona "durante un tiempo imprescindible para su comprobación"; y finamente, los artículos 16 y 17 permitirían el establecimiento de controles de identidad en "sus funciones de indagación y prevención delictiva, así como para la sanción de infracciones penales y administrativas...", pero respetando "estrictamente los principios de proporcionalidad, igualdad de trato y no discriminación por razón de nacimiento, nacionalidad, origen racial o étnico, sexo, religión o creencias, edad, discapacidad, orientación o identidad sexual, opinión o cualquier otra condición o circunstancia personal o social”. Además, el Tribunal Constitucional admitió en su sentencia 13/2001 (Caso Rosalind Williams) que “determinadas características físicas o étnicas pueden ser tomadas en consideración en ellos como razonablemente indiciarias del origen no nacional de la persona que las reúne" (FJ8) siempre que la identificación se realice "de forma proporcionada, respetuosa, cortés $\mathrm{y}$, en definitiva, del modo que menos incidencia genere en la esfera del individuo" incurriendo, en caso contrario, en "un móvil racista y xenófobo" por estar "efectuada o aprovechada para infligir un daño especial o adicional a quienes pertenecen a determinado grupo racial o étnico (FJ9). La Comisión Europea contra el Racismo y la Intolerancia $\left(2006^{13}\right.$ y $2011^{14}$ ) o el Comité de la Naciones Unidas para la Eliminación de la Discriminación Racial $\left(2011^{15}\right)$ han mostrado expresamente la necesidad de erradicar tales prácticas policiales.

Sin embargo, tanto de el alto número de detenciones (que derivan en la readmisión) como el algunas practicas policiales habituales, como es el control rutinario de trenes ¿No podemos dilucidar que se trata de un control fronterizo y no de controles de identidad por cuestiones de infracciones penales o administrativas? Tal vez, la trampa jurídica establecida tanto por la indeterminación normativa y jurisprudencial resida en la finísima línea de delimitación conceptual que separa ambas situaciones.

\section{b) El mecanismo de readmisión y los derechos del "readmitido"}

"No tienen intérprete, porque nosotros no les tomamos declaración, los franceses sí, intérprete y abogado. Nosotros en este caso tenemos un vacío legal. ¿Cómo interpretamos la ley? A la persona la controlamos en la estación de Irun, y hay que llevarla al punto de entrega de Biriatou, pero ¿en

\footnotetext{
${ }^{13}$ Enlace: https://www.coe.int/t/dghl/monitoring/ecri/Country-bycountry/Spain/ESP-CbC-III-2006-4-ESP.pdf

${ }^{14}$ Enlace: https://www.coe.int/t/dghl/monitoring/ecri/Country-bycountry/Spain/ESP-CBC-IV-2011-004-ESP.pdf

${ }^{15}$ Enlace:

http://www2.ohchr.org/english/bodies/cerd/docs/co/Spain_AUV s p.pdf
} 
Cuadernos Electrónicos de Filosofía del Derecho

calidad de qué? Nosotros no lo detenemos, lo controlamos. Es una medida necesaria para entregarlo, pero hay gente que le busca tres pies al gato y dice que tienen derecho a abogado. Según quieras interpretar la ley, pero nosotros no le tomamos declaración ni nada" (Conversación con un Policía Nacional español, CCPD).

El artículo 5, dice que los Estados contratantes se comprometen a «readmitir en su territorio, a solicitud de la otra Parte Contratante y sin formalidad alguna, al nacional de un tercer Estado que no cumpla o haya dejado de cumplir las condiciones de entrada o estancia aplicables en el territorio de la Parte Contratante requirente, siempre que se acredite que dicha persona entró en el territorio de esa Parte después de haber residido o transitado por el territorio de la Parte Contratante requerida». Este concepto de "sin formalidad alguna", rompería con toda tradición constitucional y administrativa de los derechos fundamentales según la cual en que toda acción pública que tenga como resultado gravoso, como es la deportación-readmisión, requiere de un procedimiento ajustado a Derecho (con posibilidad de información, defensa y recurso por parte del sujeto interpelado), y no solamente burocrático tal y como se recoge en los anexos y documentos adjuntos del Acuerdo. ¿No tienen los “detenidos para readmisión” el derecho fundamental a la asistencia jurídica -gratuita(artículo 24.2 CE)?
La deportación "sin formalidad alguna" se asimilaría a las denominadas "devoluciones en caliente" que España ha venido realizando en las vallas de Ceuta y Melilla, salvando la contundencia de la vallas y la violencia que allí se ejerce. Estas prácticas policiales, que han sido recientemente legalizadas por la Ley de Seguridad ciudadana que introducía una modificación de la Ley de Extranjería, han sido cuestionadas en reiteradas ocasiones por organizaciones sociales (Prodein, Asociación Pro Derecho Humanos de Andalucía, SOS Racismo, Consejo General de la Abogacía), estudios académicos (Lasagabaster 2016, Martinez Escamilla et al 2015) así como instancias institucionales españolas e internacionales (el comisario de Derechos Humanos del Consejo de Europa, Nils Muiznieks, por ejemplo). En octubre de 2017 esta norma ha sido considerada contraria al Convenio Europeo de Derechos Humanos en la sentencia del caso ND y NT contra España (Caso No. 8675/15) del Tribunal Europeo de Derechos Humanos. Estrasburgo dictaminó que España había violado el artículo 4 del Protocolo 4 del Convenio Europeo de Derechos Humanos, que establece claramente: "Las expulsiones colectivas de extranjeros están prohibidas".

En este sentido, las devoluciones "sin formalidad alguna" que se realizan entre España y Francia podrían caer dentro de la categoría de “devolución en caliente", tanto por su celeridad 
Cuadernos Electrónicos de Filosofía del Derecho

en la materialización como por la suspensión práctica de las reglas de procedimiento administrativo. En relación a las mencionadas "devoluciones en caliente" de Ceuta y Melilla, pero en esta misma línea de discusión, coincido con Solanes en que "este tipo de acciones evidencian que en la frontera, en cumplimiento de su función geopolítica y psicológica, se produce una especie de suspensión del Derecho que no es abolido por completo pero que deja paso a actuaciones que no es que sean cuestionables, sino que son directamente ilegales" (2016:156).

En el ordenamiento español, todas las figuras de deportación (Retorno por denegación de entrada 60.1 LOEX, Expulsión 57.1 LOEx, Devolución 58.3 LOEx) llevan explícitamente reconocido el derecho a la asistencia letrada, especialmente cuando los extranjeros "se hallen en España" (art 22 LOEx). Es más, según la Disposición adicional sexta LO 4/2000" “(A) los extranjeros que, en virtud de los acuerdos que regulen la readmisión de las personas en situación irregular suscritos por España, deban ser entregados o enviados a los países de los que sean nacionales o desde los que se hayan trasladado hasta el territorio español, les será de aplicación lo dispuesto en los citados acuerdos así como su normativa de desarrollo.(...) Dichos acuerdos contendrán

\footnotetext{
${ }^{16}$ Modificación introducida por el articulo 1.41LO 14/2003, de 20 de noviembre.
}

cláusulas de respeto a los derechos humanos en virtud de lo que establecen en esta materia los tratados y convenios internacionales". En todo caso, un acuerdo de la naturaleza bilateral entre dos Estados, no puede situarse ni por encima del Derecho interno de los Estados, ni del Derecho internacional (arts. 1 y 6 de la Convención Europea de Derechos Humanos) ni comunitario (art 47 de la carta de Derechos Fundamentales de Niza). Sin embargo, tal y como veremos más adelante y como han manifestado juristas $\mathrm{y}$ abogados en ejercicio (Chueca et al 2006, Puig Pellicer 2006), la práctica policial habitual española a lo largo de la frontera con Francia es la no comunicación de la detención para la readmisión al Colegio de abogados con el fin de evitar la asistencia del abogado de guardia del Turno de asistencia en materia de extranjería.

Es interesante el caso de un grupo de 230 paquistaníes que fueron detenidos en estación del EuskoTren de la Plaza Easo de San SebastiánDonostia (a $25 \mathrm{~km}$ de la frontera), a finales de abril de 2005, y fueron devueltos, sin asistencia letrada, a Francia en virtud del Acuerdo hispanofrancés de readmisión. Esta actuación policial motivó una queja por parte del Colegio de Abogados de Gipuzkoa ante la Subdelegación del Gobierno quien solicitó un Informe a la Abogacía del Estado sobre la "Forma en la que la Policía Nacional debe realizar la devolución de ciudadanos extranjeros que, en situación irregular, 
Cuadernos Electrónicos de Filosofía del Derecho

llegan al territorio español provenientes de Francia. Reconocimiento de los derechos de asistencia letrada y, en su caso, asistencia jurídica gratuita”, de 20 de mayo de 2005. Tal y como consta en el citado informe, no se puede entender que el Acuerdo implique una derogación singular del régimen de derechos y garantías aplicables a los extranjeros, y por tanto les corresponde el derecho a la asistencia jurídica gratuita por el mero hecho de encontrarse detenidos dentro del territorio.

Este caso fue resuelto por el Juzgado de lo Contencioso-Administrativo número 1 de San Sebastián, mediante Auto, de 26 de Octubre de 2005. Según el auto, se dio por finalizado el proceso con declaración de inadmisibilidad del recurso por un defecto formal -el letrado demandante interpuso el recurso en su propio nombre y derecho. No obstante, la magistrada sí que realizó una serie de importantes argumentos sobre la naturaleza de la asistencia letrada como derecho infringido: "En el presente caso es manifiesto que el recurso se interpone por el Letrado contra una actuación administrativa, ya sea de expulsión, retorno o devolución (cuestión que debería dilucidarse resolviendo sobre el fondo del asunto), sin haber garantizado el derecho a la asistencia de letrada, no ya del actor que se encontraba de guardia el día de los hechos, sino de ningún otro profesional del derecho. Ni el citado Acuerdo Hispano- Francés ni ningún otro instrumento de cooperación es título suficiente para proceder a obligar por la fuerza al abandono de España, de unas personas extranjeras que se encontraba en Donostia- San Sebastián, cerca de $20 \mathrm{~km}$. de la frontera francesa, sin seguir ningún tipo de procedimiento, ni garantizar los derechos que a estos les asisten"

Este auto hacía referencia a una Sentencia de Tribunal Superior de Justicia del País Vasco, de 24 de Enero de 2003, dictada en un supuesto de retorno, ejecutado desde la Comisaría de Policía de Irun, con fecha 10 de Mayo de 2002, sin resolución administrativa previa que amparara dicha medida: "Así las cosas nos encontramos ante un acto administrativo de ejecución (de retorno, no de detención que fue legal), realizado por los funcionarios policiales españoles sin resolución administrativa previa que le sirva de fundamento jurídico, afectando tal actuación a derechos fundamentales de la persona, $\mathrm{y}$, realizado mediante compulsión sobre las personas, por ello tal actuación de retorno a parte de vulnerar el derecho fundamental a tutela judicial efectiva del art. $24 \mathrm{CE}$ supone una trasgresión de lo previsto en el art. 93 y 100 de la Ley 30/92, 26 de noviembre en tanto que la Administración ha ejecutado una Resolución de retorno sin la previa adopción de ésta, ni por tanto su notificación en forma, y ha de calificarse de una actuación administrativa nula radicalmente 
Cuadernos Electrónicos de Filosofía del Derecho

por lesionar derechos fundamentales susceptibles de amparo constitucional".

También es interesante el caso de un grupo de 150 ciudadanos rumanos que fueron devueltos por España a Francia por Irun en julio de 2006. En este caso concreto, la Sentencia del Juzgado Contencioso Administrativo $\mathrm{n}^{\mathrm{o}} 1$ de Donostia (133/2007), versaba sobre el recurso que una ciudadana rumana interpuso contra la Readmisión porque ésta se realizó sin asistencia letrada desde el inicio. Este tribunal aquí sí sentenció que esta actuación cera constitutiva de vía de hecho (actuación administrativa irregular por violación de derechos fundamentales). La Sentencia de Apelación del Tribunal de Justicia del País Vasco (570/2009), en este caso, estimó recurso del Estado, quien solicitaba que no se reconociera la representatividad al letrado del turno de guardia puesto que no había habido una designación directa por parte de esa ciudadana rumana. Con todo, el Tribunal de apelación no entró a la cuestión de si correspondía o no derecho a asistencia. Simplemente dijo que los "el artículo 24.2 de la Constitución inequívocamente confiere derechos fundamentales a las personas extranjeras que se encuentran en territorio español y se ven sujetas a una actuación administrativa de privación de libertad en las dependencias policiales de los puestos de control de fronteras a efectos de instrucción del procedimiento de devolución y, en su caso, de cumplimiento del Acuerdo de Readmisión suscrito con Francia”.

c) Criterio temporal vs el criterio espacial de la interceptación/detención.

"Si por ejemplo hemos controlado a la persona a las 12:00 y a las 12:30 ya lo tienen los franceses, pues es una medida necesaria y bien hecha. Si lo controlas a las 12:00 y lo quieres llevar más de cuatro horas después ahí ya podemos tener problemas". (Conversación con un Policía Nacional español, CCPD)

Por su parte, el artículo 7 del Acuerdo de referencia dispone lo siguiente: «Las autoridades de frontera de cada una de las partes contratantes readmitirán inmediatamente en su territorio a los extranjeros, nacionales de un país tercero, que sean presentados, por las autoridades de frontera de la otra parte, dentro de las cuatro horas posteriores al paso ilegal de la frontera común". Ya hemos dicho que las solicitudes deben responderse en un plazo máximo de 72 horas. Ahora bien, las solicitudes deben plantearse antes de las 4 horas desde el cruce. Este criterio temporal podría entrar en colisión con el criterio espacial empleado por ejemplo en los Artículos $58.2 b)$ de la Ley de Extranjería y el 23 del Reglamento de la Ley de Extranjería ${ }^{17}$, el cual

\footnotetext{
${ }^{17}$ Real Decreto 557/2011, de 20 de abril, por el que se aprueba el Reglamento de la Ley Orgánica 4/2000, sobre derechos y libertades de los extranjeros en España y su integración social, tras su reforma por Ley Orgánica 2/2009.
} 
Cuadernos Electrónicos

de Filosofía del Derecho

dice que serán devueltos "los extranjeros que pretendan entrar irregularmente en el país", incluyendo "los extranjeros que sean interceptados en la frontera $o$ en sus inmediaciones".

A diferencia de otros ordenamientos en los que se delimita expresamente un perímetro fronterizo, aquí se emplea al concepto indeterminado de "inmediaciones". A este respecto el Tribunal Supremo, en la sentencia de 20 de marzo de 2003, anuló varios preceptos del Reglamento 864/2001 porque extralimitaban el contenido de la Ley de Extranjería al extender la posibilidad de devolución, no solo "en la frontera o en sus inmediaciones", sino también "en el interior del territorio nacional en tránsito o en ruta". $\mathrm{Si}$ el Supremo estimó que no cabría considerar posible una devolución una vez accedido al territorio lo suficiente como para considerarlo "en el interior, en tránsito o en ruta", en todo caso, el plazo de 4 horas permitiría una detención a cientos de kilómetros alejándose claramente de la "inmediaciones de la frontera". Por tanto, la Ley orgánica de extranjería y el reglamento de desarrollo (incluyendo la jurisprudencia sobre los casos concretos) prevalecerían sobre un acuerdo bilateral, debiéndose impedir la aplicación de este acuerdo para los casos en los que la interceptación/detención no se produzca estrictamente cerca de la frontera o sus inmediaciones en sentido estricto. Dicho de otra manera, más allá de la inmediaciones de la frontera, en el centro de Donostia-San Sebastián, a 25 kilómetros por ejemplo, se trataría de una detención que requeriría la incoación de un expediente de expulsión (57.1 LOEx), y no cabría la mera readmisión.

\section{Conclusiones}

A pesar de que el País vasco es un territorio donde la población extranjera no es especialmente significativa, ni donde los cuerpos de policía que más implantación tienen (Ertzaintza y policía local) no tienen competencias en extranjería, la tasa de detenciones por infracción de la ley de extranjería se encuentra en crecimiento con respecto al total del Estado. Es especialmente en Gipuzkoa donde la comisaría de Irun, por su demarcación fronteriza, presenta una tasa que multiplica las otras comisarías implantadas en el territorio. Pese a la percepción generalizada de que existe un euro-comunidad, fruto de la libertad de circulación por la eliminación de las barreras fronterizas, en el País Vasco, entre los Estados español y francés, existe una frontera (interna) con aproximadamente 1500 deportados anuales. Esto la caracteriza como una frontera muy activa en términos de control de la inmigración irregular, por encima de otros pasos a lo largo de la frontera. 
Cuadernos Electrónicos

de Filosofía del Derecho

A pesar de las prácticas policiales a las que se ha hecho referencia a lo largo de la última parte del artículo, a las personas que son objeto de readmisión, en tanto que se produce en el marco de un procedimiento administrativo-burocrático que implica una deportación, según la ley de extranjería y otras normas constitucionales e internacionales, el derecho a la asistencia jurídica (gratuita) es de obligada observación. Esto último implicaría que desde el momento en que se produce el control, independientemente del tiempo en que se tarde en efectuar la readmisión, la persona controlada, está detenida para su expulsión y por tanto, en virtud del 520 LECrim y 22 LOEx, es su derecho ser asistida por un abogado de confianza o por el abogado de guardia del Turno de extranjería del Colegio de Abogados.

En definitiva, tras este análisis con pretensiones exploratorias pero con elementos empíricos contrastables e irrevocables argumentos jurídicos, queda en cuestión el mito de la Europa sin fronteras. A la vista de los datos y de los discursos contenidos en los documentos de soft law de las instituciones europeas, en el futuro es posible que se generalicen los controles de identidad, especialmente en las zonas fronterizas. Esta situación, por efecto mimético, puede dar lugar a una reintroducción de facto de las fronteras, en consecuencia al destierro de uno de los elementos definitorios del proyecto europeo como es la libertad de circulación. 


\section{Bibliografía:}

BALIBAR, E.; Violencias, identidades y civilidad. Para una cultura politica global. Barcelona: Gedisa, 2005.

BIGO, D.; "Immigration controls and free movement in Europe", International Review of the Red Cross, 2009, Vol. 91, N. 875 ,

BIGO, D., BROUWER, E., CARRERA, S., GUILD, E., GUITTET, E. P., JEANDESBOZ, J.,y SCHERRER, A.; The EU counter-terrorism policy responses to the attacks in Paris: Towards an EU security and liberty agenda. CEPS Papers in Liberty and Security in Europe, 2015, (81).

BRAY, Z. 'Boundares in a 'borderless' Europe: European Integration and Cross-Frontier Cooperation in the Basque Country', in (Harlan Koff ed.) Deceiving (Dis)Appearances: analyzing current developments in European and North American border regions. Brussels: PIE Peter Lang, 2007.

CHUECA, A; AGUELO, P, ALMANDOZ, I; PUIG PELLICER, JR; BATALLA, M.; Informe sobre la problemática de la asistencia letrada en las fronteras interiores Schengen. Subcomisión de Extranjería del Consejo General de la Abogacía, 2006.

EL ARBI, M.; "Readmission agreements: The Case of Morocco," European Journal of Migration and Law, 2010, 5, pp 379-385.

DE LUCAS, J.; Mediterráneo: el naufragio de Europa. Tirant Humanidades, 2015.

FAJARDO DEL CASTILLO, T.; "Los acuerdos de readmisión de los inmigrantes en situación irregular celebrados por España" en ALDECOA LUZÁRRAGA, F., SOBRINO HEREDIA, J. M. (coord.),
Migraciones y Desarrollo, Marcial Pons, Madrid, 2007, pp. 407 y ss.

GUILD, E.; Security and Migration in the 21st Century. Polity, 2009.

KLEPP, S.; A contested asylum system: The European Union between refugee protection and border control in the Mediterranean Sea. European Journal of Migration and Law, 2010, 12(1), 1-21.

LAFOURCADE, M. ; 'La frontière francoespagnole, lieu de conflits interétatiques et de collaboration interrégionale', in $\mathrm{M}$. Lafourcade (ed.), La Frontière FrancoEspagnole: lieu de conflits interétatiques et de collaboration interrégionale. Actes de la journée d'études du 16 novembre 1996, Biarritz: Presses Universitaires de Bordeaux, 1998.

LASAGABASTER, I.; "La regulación de la expulsión de extranjeros en la ley de seguridad ciudadana y la prohibición de tratos inhumanos y degradantes. Breve consideración sobre la situación en la frontera de Ceuta y Melilla" en ARRESE IRIONDO, Nieves y BARBERO, Iker (coords.), Tensiones entre las políticas de extranjería y los Derechos Humanos, Tirant lo Blanch, Colección Derechos Humanos, 2016, pp.117-142

MANGAS, A.; "Algunos desarrollos jurisprudenciales sobre asilo e inmigración irregular en la Unión Europea". en Estudios de Derecho Internacional y Derecho Europeo en Homenaje al Prof. Manuel Pérez González. Tirant lo Blanch, Valencia, 2012, pp. 1629-1644

OBSERVATORIO HISPANO - FRANCÉS de TRÁFICO en los PIRINEOS; Principales Cifras actualizadas paras los año 2013 y 2014. Ministerio de Fomento

OLESTI RAYO, A. O.; "El Espacio Schengen y la reinstauración de los controles en las fronteras interiores de los Estados miembros de la Unión Europea". Revista 
Cuadernos Electrónicos

de Filosofía del Derecho

d'estudis autonòmics $i$ federals, (15), 2016, 44-84.

PUIG PELLICER, JR,; “Asistencia letrada en la frontera de la Jonquera". Revista de Derecho migratorio y extranjería, 13, 2006, págs. 279-282

SCHIEFFER, M.; "Community readmission agreements with third countriesobjectives, substance and current state of negotiations". European Journal of Migration and Law, 2003, 5(3), pp. 343357.

SOLANES, A.; "Una reflexión iusfilosófica y política sobre las fronteras". Anuario de Filosofía del Derecho, 2016, num 32, pp. 145-184

STRIK, T.; "Readmission Agreements: A Mechanism for Returning Irregular Migrants”, Doc. 12168, 16 March 2010. Strasbourg: Parliamentary Assembly of the Council of Europe.
TRIANDAFYLLIDOU, A. (Ed.); Irregular migration in Europe: myths and realities. Routledge, 2016.

VAN DER WOUDE, M., y VAN BERLO LLM MSc, P.; Crimmigration at the Internal Borders of Europe? Examining the Schengen Governance Package, Utrecht Law Review, , 2015, Vol. 11, No. 1, pp. 61-79.

VAN DER WOUDE, M., \& VAN DER LEUN, J.; Crimmigration checks in the internal border areas of the EU: Finding the discretion that matters. European journal of criminology, 2017, 14(1), 27-45. 